\author{
AlAhmady Hamad AlSamman*, Ashraf \\ Mostafa Moahammed and Usama Ali \\ Mohammed \\ Department of Ophthalmology, Faculty of Medicine, \\ Sohag University, Egypt \\ Dates: Received: 01 November, 2016; Accepted: \\ 09 November, 2016; Published: 15 November, 2016 \\ ${ }^{*}$ Corresponding author: Alahmady Hamad \\ Alsmman, MD, Department of Ophthalmology, \\ Faculty of Medicine, Sohag University, 82524 \\ Sohag, Egypt, Tel: 0020-11 11102698 ; E-mail: \\ alahmady20@yahoo.com \\ www.peertechz.com
}

ISSN: 2455-1414

Keywords: Phakic IOL; Myopia; Refractive surgery

\author{
Research Article
}

\section{Anterior Chamber Foldable Phakic Intra Ocular Lens Safety and Efficacy}

\section{Abstract}

Purpose: Correction of myopia by implantation of intra ocular lens is a growing surgery. In this study I am trying to assess the visual outcome stability and safety of eyes undergoing Anterior chamber foldable phakic lens implantation (Artiflex) (Ophtec BV, Groningen, The Netherlands) or (veriflex) (AMO,Santa Ana,CA) for myopia unsuitable for LASIK and detection of early and late complications along three years follow up period.

Methods: A retrospective analysis of 25 eyes of 16 patients underwent Anterior chamber foldable phakic IOL (Artiflex) or (Veriflex) implantation for correction of myopia all patients were unsuitable for LASIK all patients underwent surgery with one surgeon in same circumstances. Uncorrected visual acuity, corrected visual acuity (BCVA), higher-order aberrations, patient satisfaction, central endothelial cell count, and PIOL position centration and incarcerated iris tissue were determined along follow up period

Results: At the end of the 36 months of follow up period 14 of the 25 eyes (56\%) achieved BCVA better than that measured pre-operatively and 10 of the 25 eyes $(40 \%)$ matched their pre-operative BCVA. One eye (4\%) attained a final BCVA worse than pre-operatively, due to recurrent uveitis. One patient $(4 \%)$ need another surgery to fixate the lens due to slippage of incarcerated iris tissue with impending displacement.

Conclusions: This study suggests that Anterior chamber foldable phakic IOL (iris claw lens insertion) Artiflex or Veriflex is beneficial in myopia, unsuitable for LASIK, matching or exceeding preoperative BCVA in the overwhelming majority of the cases. With no major complications however long standing follow up is needed to avoid major complications.

\section{Abbreviations}

PIOL: Phakic Intra Ocular Lens; IOL: intraocular Lens; LASIK: Laser Insitu Keratomeleiosis; PRK: Photorefracive Keratectomy; BCVA: Best Corrected Visual Acuity; UCVA: Uncorrected Visual Acuity; PMMA: Poly Methel Metha Arylate; ACD: Anterior Chamber Depth; ECD: Endothelial Cell Count; SE: Spherical Equivilant

\section{Introduction}

Most of patients are hoping to see well without spectacle or contact lenses. So in last years the refractive surgery increased in patients dissatisfied with spectacles and contact lenses either due to quality of vision, cosmetic appearance or difficulties in contact lenses wearing and its complications. corneal surgeries like corneal ablation ( photorefractive keratectomy (PRK) and laser-assisted in situ keratomileusis LASIK) and different types of phakic intraocular lens (PIOL) implantation either in the anterior or posterior chamber and the anterior chamber either iris claw or angle fixation IOL aim to correct s refractive errors in myopic patients [1,2].

Corneal surgeries, such as photorefractive keratectomy (PRK) and LASIK, have many limitations and contraindications especially for the correction of high refractive errors. Postoperative ectasia which is a major problem can occur with removing of too much corneal tissue to correct high myopia with the laser. Night bad quality vision and dry eye complaints may be transient or permanent symptoms which may cause dissatisfaction for refractive patients. Due to these limitations and complications, indications for corneal refractive surgery have narrowed [3-6].
As many patients with myopia unsuitable for LASIK the Intraocular refractive procedures may be a good alternative: high degrees of ametropia thin corneas and keratoconus suspect can be corrected, more stable refraction, better visual quality in day and night and lastly reversibility of our technique all of above make intraocular refractive surgery is a good alternative in patients refusing glasses and contact lenses $[7,8]$.

Intraocular refractive surgeries may be classified into: phakic intraocular lens (PIOL) implantation with preservation of crystalline lens and clear lens extraction with lens implantation, also called refractive lens exchange. Clear lens extraction may increases the risk for retinal detachment and is generally not preferable in myopic prepresbyopic patients who can still accommodate as it deprive them from useful accommodation and always patient suffers from disability of near vision without glasses. Retinal detachment after refractive lens exchange for high myopia is always present and has been described to occur in $2 \%$ to $8 \%$ of patients which increase if complications occurred during surgery $[9,10]$.

PIOL implantation in suitable patients may be more favorable than other refractive surgery techniques, the PIOL is potentially reversible as the PIOL is removable surgically with any major complication. Visual recovery is fast, and accommodation is preserved with great benefit in pre presbyopic patients. Implantation of a PIOL utilizes operative techniques familiar to most anterior segment surgeons and does not require expensive or specialised devices, such as an 
excimer laser. On the other hand complications relating to PIOLs can be more disabling than those from keratorefractive surgery. Glaucoma, cataract formation, corneal decompensation, uveitis, and endophthalmitis are potential complications after PIOL insertion [11].

In the 1980s, as an increasing number of reports indicated complications from use of the angle-supported PIOLs, a new type of anterior-chamber PIOL was developed based on the 1977 design of Jan Worst's iris-fixated "iris-claw" lens [12-14].

The name of the PIOL was changed to Artisan (Ophtec BV, Groningen, The Netherlands), and it is available for myopic patients with powers from -3 to $-23.5 \mathrm{D}$. In 2004, the PIOL gained FDA approval under the name Verisyse Phakic IOL (Abbott Medical Optics, Inc., Santa Ana, CA), with available powers from -5 to -20 D. A toric Artisan model is also available in Europe with parameters similar to the Artisan, but with cylindrical powers up to -7.5D [1517].

The Artiflex and Veriflex foldable IOLs are a three-piece lenses were developed based on the Artisan design, with a flexible, $6.0-\mathrm{mm}$ convex-concave silicone optic, PMMA haptics, and overall diameter of $8.5 \mathrm{~mm}$.

Myopic IOL is available in powers of -2 to $-14.5 \mathrm{D}$, and it utilizes a small $(3.2 \mathrm{~mm})$, self-sealing incision, thereby allowing for more rapid recovery of visual acuity. The Artiflex has Conformité Européene marking in the European Union and is undergoing FDA clinical trials as the Veriflex lens (Abbott Medical Optics, Inc.) [18].

\section{Aim of the work}

To assess the visual outcome stability and safety of eyes undergoing anterior chamber foldable phakic lens implantation (Artiflex and veriflex) for myopia unsuitable for LASIK and detection of early and late complications along three years follow up period.

\section{Materials and Methods}

In this study Helsinki guidelines were followed.

Twenty five eyes of 16 patients included in this study. Artiflex or Veriflex PIOL for correction of myopia was implanted in patients unsuitable for LASIK due to thin cornea, abnormal pentacam or refraction out of range of correction. This study were done between March 2010 and March 2012, in a retrospective study. Inclusion criteria were patient age above 18years up to 40 years, in patients from 18 to 25 years stability of refraction for 6 months was mandatory, mesopic pupil size equal to or less than $6.5 \mathrm{~mm}$, an anterior chamber depth (ACD) equal to or more than $2.85 \mathrm{~mm}$, endothelial cell count more than 2000 cells/mm2, no history of previous ocular pathology like iritis, glaucoma, retinal detachment, retinal tear nor hole. No history of any intra ocular surgery including previous refractive corneal surgery. A written informed consent was obtained from all patients after full details about the procedure, its advantages and disadvantages and suggested complications. The study was done in Ophthalmology department Sohag Faculty of Medicine Sohag Egypt.

Patients were examined before the surgery, including uncorrected visual acuity (UCVA), best-spectacle corrected visual acuity (BSCVA),) refraction both manifest andand after complete cycloplegia by cyclopentolate $1 \% 6$ hours before examination and the spherical equivalent (SE) were calculated, meticulus slit-lamp examination for the anterior segment, pupil size by manualcard comparison method was measured, corneal topography endothelial cell density (ECD), applanation tonomety by tonopen and fundus examination by direct and indirect ophthalmoscopy for detection of peripheral retinal abnormalities . UCVA and BSCVA were measured in decimal Snellen and converted to the logarithm of the minimum angle of resolution $(\log M A R)$. Corneal endothelium count was evaluated by use of Topcon noncontact specular microscope.

The calculation of the IOL power was done by using van der Heijde formula, which uses the corneal curvature, ACD, and manifest $\mathrm{SE}$ of the refractive error at a vertex distance of $12 \mathrm{~mm}$, the calculation was done in each cases by the manufacturing company.

\section{Surgical technique}

Before the surgery by one hour, topical antibiotic Vigamox (moxifloxacin hydrochloride ophthalmic solution 0.5\%) with pilocarpine $2 \%$ (isoptocarpine) was installed in the conjunctival sac of all eyes every 15 minutes 4 times the miotics installed in order to ease lens fixation in the iris tissue and avoid pupil dilation after anaesthesia and protection of crystalline lens from touch during implantation. Surgeries were performed by same surgeon and under same circumstances all surgeries were done under general anaesthesia only $3 \mathrm{~mm}$ clear corneal incision was performed at 12 o'clock by keratome, the anterior chamber reformation by viscoelastic material (Healon GV, Abbott Medical Optics, Santa Ana, CA, USA) and two paracentesis were located at 10 o'clock and 2 o'clock. The PIOL was loaded on special spatula (Operaid Artiflex Implantation Spatula, Ophtec, Groningen, and the Netherlands) and introduced into the anterior chamber through keratome opening the lens after introduction it will be in vertical position from 12 to 6 o'clock there after rotated $90^{\circ}$ into a horizontal position from 3 o'clock to 9 o'clock.

Fixation of the PIOL to the iris was done by catching the PMMA haptic by special curved forceps as the optic is foldable and any hold to the optic of no value. the iris tissue was enclavated into the haptics with the aid of Operaid Artiflex Enclavation Needle or simply be insulin needle after curving its tip 90 degree introduced from side pore for the right haptics and then repeated for the left one . A peripheral iridectomy was done surgically at 12 o'clock and the viscoelastic material was washed out with balanced solution. Hydration of the edges of the wound was done the wound usually is water tight and need no sutures however safety suture was placed to prevent wound leakage if needed. Postoperative drugs including Vigamox (moxifloxacin hydrochloride ophthalmic solution $0.5 \%$ Alcon) and prednisolon acetate( Pred forte Allergan) four times per day the first for one week and the second for one month and gradually withdrawn acetazolamide 250mg orally (cidamex Tablets )twice daily for three days only (Figures 1-3).

All patients followed up at the same day 8 hours after surgery then 1 day, 1 week, 1 month, 3 months, 6 months, 12 months and 24 months and 36 months after the surgery and advised to follow up every year after that. 
In all patients visual acuity, meticulus slit-lamp examination with detection of centration, endothelial cell density (ECD) and applanation tonomety in all visits were done.

Statistical analyses were performed using SPSS. Preoperative and postoperative mean outcome measurements were compared using paired $\mathrm{t}$ test (when data were normally distributed) A two-tailed probability of $5 \%$ or less was considered statistically significant.

\section{Results}

25 eyes of 16 patients included in this study 10 female and 6 male patients the preoperative data showed in Table 1.

The mean preoperative $\log$ MAR BSCVA was $0.23 \pm 0.21$ (range $0-1$ ). The mean BSCVA was $0.15 \pm 0.14$ (range -0.1 to $0.5, P<0.05$ ) at the first year, $0.15 \pm 0.14$ (range -0.1 to $0.5, P<0.05$ ) at the second

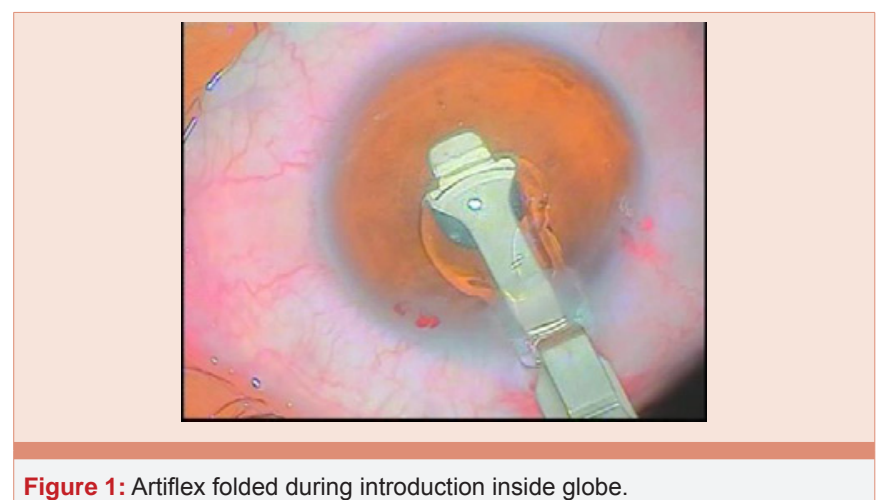

Figure 1: Artiflex folded during introduction inside globe.

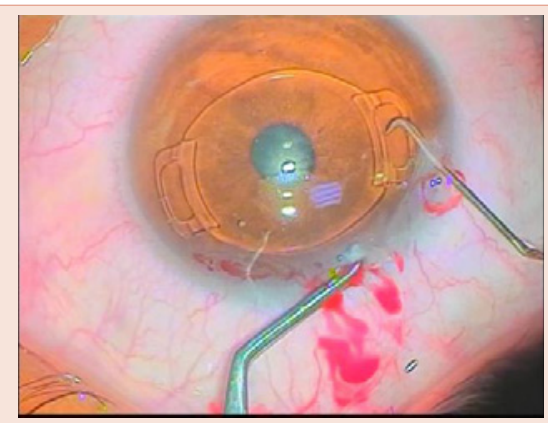

Figure 2: Fixation of the right haptic.

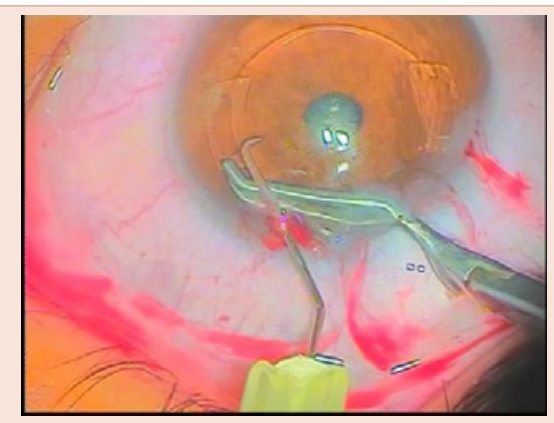

Figure 3: Fixation of the left haptic.
Table 1: Preoperative and operative data of the patients who underwent Artiflex or Veriflex phakic intraocular lens implantation.

\begin{tabular}{|l|l|}
\hline Item & Descriptive "n=25" \\
\hline eye: & \\
Right & $14(56.0 \%)$ \\
Left & $11(44.0 \%)$ \\
Age "yrs." & \\
mean \pm SD & $27.70 \pm 7.10$ \\
(min-max) & $(19.0-40.0)$ \\
& \\
Refraction "Diopters" & $-9.0 \pm 3.5$ \\
SE "Diopters" & $9.85 \pm 4.72$ \\
ECC (cells/mm) & $3122 \pm 345$ \\
ACD & $3.44 \pm 0.33$ \\
PIOL power "Diopters" & $6.0-14.5$ \\
\hline SD Standard deviation, SE
\end{tabular}

SD standard deviation, SE spherical equivilant, ECC endothelial cell count, ACD anterior chamber depth,PIOL phakic intraocular lens.

\begin{tabular}{|l|l|}
\hline \multicolumn{1}{|l|}{ Table 2: BSCVA preoperative and follow-up. } \\
\hline Item & Descriptive "n=25" \\
\hline Preoperative & $0.23 \pm 0.21$ \\
& $(0.0-1.0)$ \\
First year & $0.15 \pm 0.14$ \\
& $(-0.1-0.5)$ \\
& $\mathrm{P}<0.05^{\star}$ \\
Second year & $0.15 \pm 0.14$ \\
& $(-0.1-0.5)$ \\
& $\mathrm{P}<0.05^{\star}$ \\
Third year & $0.14 \pm 0.15$ \\
& $(-0.1-0.7)$ \\
& $\mathrm{P}<0.05^{\star}$ \\
\hline Line gained: & \\
1month & $12(48.0 \%)$ \\
1year & $16(64.0 \%)$ \\
2year & $18(72.0 \%)$ \\
3year & $21(84.0 \%)$ \\
Improvement in BSCVA: & \\
First year & $20(80.0 \%)$ \\
Second years & $19(76.0 \%)$ \\
Third years & $21(84.0 \%)$ \\
safety index: & \\
First year & 1.03 \\
Second years & 1.1 \\
Third years & 1.12 \\
& \\
\hline
\end{tabular}

year and $0.14 \pm 0.17$ (range -0.1 to $0.7, P<0.05$ ) at the third year after the operation. At the end of the third year, BSCVA was decreased 2 lines in one eye (4\%). After 1 month 48\% (12 of 25 eyes) gained 1 line or more of BSCVA, after 1 year 64\% (16 of 25 eyes) gained 1 line or more of BSCVA, after 2 year $72 \%$ ( 18 of 25 eyes) gained 1 line or more of BSCVA, and after 3 years, $84 \%$ (21 of 25 eyes) of eyes gained 1 line or more of BSCVA,. BSCVA was 20/40 or better in 20 eyes (80\%), 19 eyes $(76 \%)$ and 21 eyes $(84 \%)$ of the eyes at the first year, and at the second and third years, respectively (Figure 4).

In our patients the safety index (the ratio of mean postoperative Snellen BSCVA to mean preoperative Snellen BSCVA) was 1.03 after one year, 1.10 after two years and 1.12 after 3 years (Table 2).

The mean preoperative logMAR UCVA of $1.33 \pm 0.37$ (range $0.6-1.9$ ) was improved to $0.27 \pm 0.26$ (range -0.1 to $1, P<0.001$ ) after 
3 years. UCVA was $20 / 40$ or better in $80 \%, 76 \%$ and $84 \%$ of eyes after 1 year, 2 years and 3 years, respectively (Figure 5 ). The efficacy index in our patients (the ratio of mean postoperative Snellen UCVA to the mean preoperative Snellen (BSCVA) was $0.71,0.76$ and 0.8 at the first year, and at the second and third years, respectively (Table 3 ).

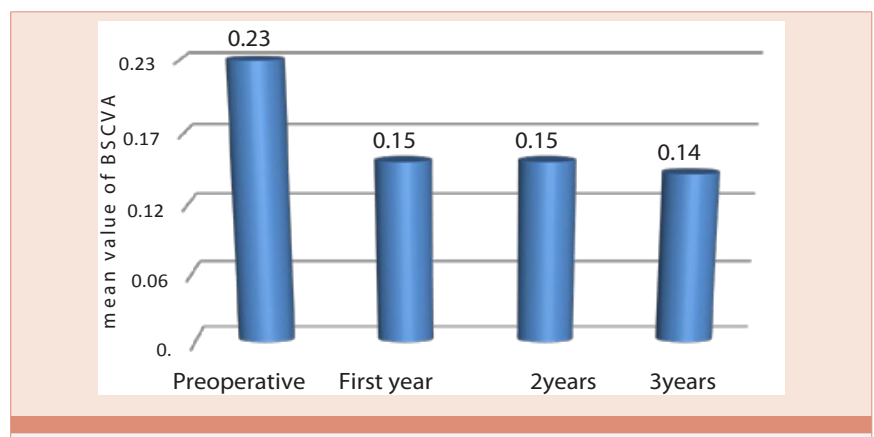

Figure 4: Change in BSCV 1year 2 years, 3 years a preoperative and followup.

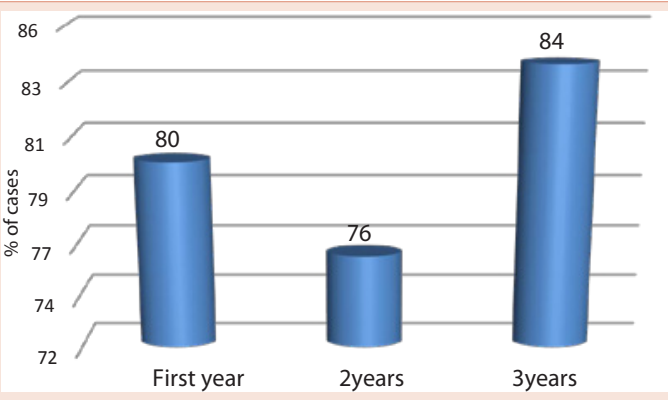

Figure 5: Improvement in logMAR UCVA.

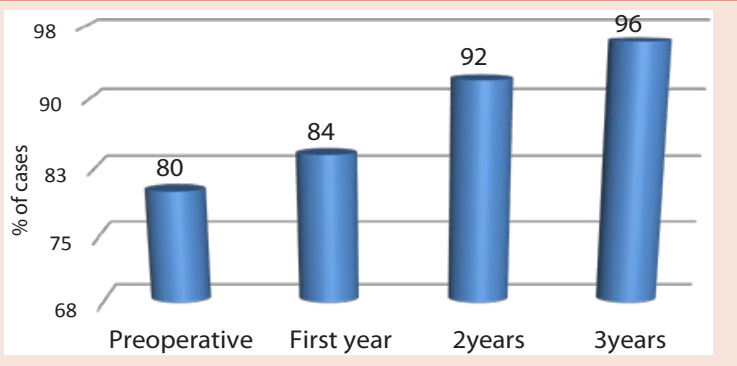

Figure 6: SE correction with follow-up.

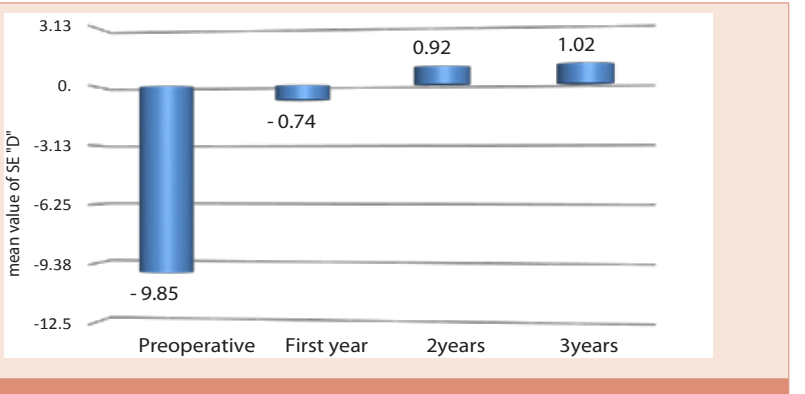

Figure 7: Change in SE pre-operative and postoperative follow-up.

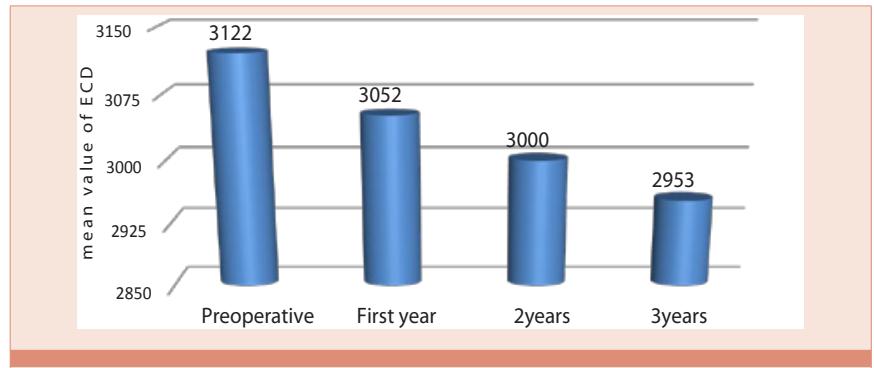

Figure 8: The mean ECD before and after the surgery.

Table 3: logMAR UCVA preoperative and follow-up.

Item

Descriptive " $\mathrm{n}=\mathbf{2 5}$ "

Preoperative

$1.33 \pm 0.37$

$(0.6-1.9)$

Third year

$0.27 \pm 0.26$

$(-0.1-1.0)$

$\mathrm{P}<0.001$ **

Improvement in MAR UCVA:

First year

Second years

Third years

Efficacy index:

First year

Second years

Third years

$20(80.0 \%)$

$19(76.0 \%)$

$21(84.0 \%)$

0.71

0.76

0.80

\section{Table 4:}

Item

Descriptive " $\mathrm{n}=25$ "

Pre-operative

First year

Second year

Third year

$-9.85 \pm 4.72$

$-0.74 \pm 0.8$

$0.92 \pm 0.77$

$-1.02 \pm 0.7$

Table 5: Complications after Artiflex phakic intraocular lens implantation (Ophtec BV, Groningen, The Netherlands).

\begin{tabular}{|l|l|}
\hline Item & Descriptive "n=25" \\
\hline IOP & $8.0 \%$ \\
Glare and halos & $8.0 \%$ \\
pigmented deposits & $16.0 \%$
\end{tabular}

About the correction of refractive errors the postoperative achieved refraction from the wanted refraction was detected. After one year $80 \%$ ( 20 of 25 eyes) of the eyes were within $\pm 0.5 \mathrm{D}$ of the needed refraction, while $84 \%$ ( 21 of 25 eyes) at the end of the second year and $92 \%$ ( 22 of 25 eyes) of the eyes at the end of the third years. After 3 years, $96 \%$ ( 24 of 25 eyes) of the eyes were within $2.0 \mathrm{D}$ of the desired refraction (Figure 6).

Preoperatively mean SE in the myopic patients was $-9.85 \pm 4.72$ diopters. After 1 year postoperatively the mean SE was $-0.74 \pm 0.8 \mathrm{D}$ (range -2.00 to $1.00 \mathrm{D}$ ), after 2 years was $-0.92 \pm 0.77$ (range -2.50 to $1.00 \mathrm{D}$ ), and after 3 years the improvement was $-1.02 \pm 0.7 \mathrm{D}$ (range -2.50 to $0.50 \mathrm{D}$ ) (Figure 7) (Table 4).

\section{Endothelial cell changes}

The mean preoperative ECD was $3122 \pm 345$ cells $/ \mathrm{mm}^{2}$ (range 2777 to $3467 \mathrm{cell} / \mathrm{mm}^{2}$ ). A year after surgery, the mean ECD was 3052 
\pm 422 cells $/ \mathrm{mm}^{2}$. At the second year, the mean ECD was $3000 \pm 321$ cells $/ \mathrm{mm}^{2}$ and in the third year endothelial cell count was $2953 \pm 433$ cells $/ \mathrm{mm}^{2}$. The mean endothelial cell loss after 1 year was $2.23 \% .2$ years was $3.9 \%$ and 3 years was $5.4 \%$. Figure 8 shows the mean ECD before and after the surgery.

\section{Complications}

There were no intraoperative complications however difficulty in centration with recenteration in some early cases elongates the operative time but without recorded complications. IOP was found to be increased in two eyes (8\%), both in the same patient with rapid control by beta blocker only and shift from steroid to non-steroidal anti-inflammatory drops which suggesting it was steroid sensitive patient.

In one eye one year later the iris tissue between one of haptics show atrophy with impending dislocation of the IOL and another surgery under local anaesthesia was done with refixation of the IOL. Glare and halos were observed in 2 eyes $(8 \%)$ of. Glare and halos were explained by poor centration of the phakic IOL in one eye and a large scotopic pupil size in the other eye however adaptation with clinical improvement in few post-operative months. One eye (4\%) show postoperative iritis rapidly reserved in few days however another attack of iritis within three months occurred affecting the vision however resolution occurred with frequent steroids but non pigmented precipitate persist decreasing the vision. pigmented deposits were found in four eyes (16\%). These eyes were treated with topical corticosteroid agents, but pigment precipitates persisted in these eyes. These eyes, however, did not have a loss of visual acuity. Complications are summarized in Table 5.

\section{Discussion}

In many cases of myopia and hyperopia out of range of LASIK and in cases unsuitable for LASIK due to corneal thinning or abnormal pentacam, and provide immediate improvement in visual acuity with great advantage of preservation of accommodation phakic IOLs are good alternative [19]. The implantation of anterior chamber irisfixated PIOLs has been shown to be an effective surgical option for the treatment of refractive errors, with optical quality superior to that of corneal refractive surgeries [14-18]. The efficacy and safety of the Artisan iris-claw lens has been demonstrated in several multicenter studies [20,21]. However, a large $6 \cdot 2-\mathrm{mm}$ corneal incision was needed for the implantation of the rigid made of PMMA material Artisan iris-claw lens with suturing of the large wound. The Artiflex lens has been developed based on the Artisan concept, with rigid haptics made of PMMA with the same technique of iris fixation and foldable optic made of silicon facilitate introduction through narrow opening .

The added value of the foldable anterior chamber Artiflex over the Artisan is that it can be inserted through a $3.2 \mathrm{~mm}$ small corneal incision with no suturing [18]. In this study we use $3 \mathrm{~mm}$ incision and noticed that it is easy to introduce through the smaller incision with good sealing wound and rapid recovery.

In the current study we evaluated the effectiveness, safety and potential complication of the implantation of Artiflex or veriflex foldable iris-fixated phakic IOLs for the management of myopia unsuitable for LASIK in a three years which is relatively long postoperative follow up period.

Alexander et al. [14], reported efficacy and predictability of the iris-fixated lenses by using the rigid PMMA model In their study comprising 264 phakic eyes, reported a significant improvement of BCVA with $100 \%$ of patients achiving $20 / 40$ or better, $72 \%$ gaining 1 or more lines on snellens chart while $22 \%$ gaining 2 or more lines. In the European multicenter study [21], the predictability, with Artisan lenses, $57.1 \%$ of the eyes were within $\pm 0.5 \mathrm{D}$ of the wanted correction and $78.8 \%$ were within $\pm 1.0 \mathrm{D}$ after 3 years of surgery. Also, in the Food and Drug Administration study [20], 55\% of the eyes were within $\pm 0.5 \mathrm{D}$ of the wanted correction and $76 \%$ of the eyes were within \pm 1.0 D after 6 months. In 2005, Tehrani and Dick [18], reported the first clinical study describing the performance of a foldable irisfixated anterior chamber lens for the correction of myopia in phakic eyes. Their results denoted that this lens is a predictable, stable, and efficient option for the correction of myopia. In their study, after six month UCVA was improved in all eyes and $76 \%$ of the eyes impoved 1 or 2 lines on snellens chart of BSCVA. Successful visual outcomes of Artiflex PIOL implantation were also reported 4 years later, in the European multicenter study [22], $75.2 \%$ of the eyes were within \pm 0.5 D of the wanted correction and $94.3 \%$ of the eyes were within \pm 1.0 $\mathrm{D}$ after 2 years follow up. In the present study, we founded that the implantation of the foldable iris-fixated anterior chamber intraocular lens corrected myopia with a high degree of predictability and stability, and provided improvement in both UCVA and BSCVA in the 3-year follow-up period.

UCVA were $20 / 40$ or better in $84 \%$ and BSCVA were $20 / 40$ or better $80 \%$ of the eyes. The predictability of the procedure was found satisfactory, with $92 \%$ of the treated eyes within \pm 0.50 of the wanted correction.

The corneal endothelium may be in danger in cases of anterior chamber intraocular lenses. It is well known that the endothelial cell count decreases with progress in age. the endothelial cell count in more risk in cases of shallow anterior chamber, extensive eye rubbing, or IOL displacement resulting from inadequate iris fixation or due to trauma even after long duration which may end in corneal decompensation and mandatory keratoplasty [17]. Progressive endothelial damage may be caused by mechanical contacts between the PIOL and corneal endothelium. Several studies have reported short- and long-term complications related to these lenses however AC less than 2.8 was of exclusion criteria of this study and we think endothelial damage occur in shallow AC.

Saxena et al. [23], showed a significant decrease in ECD after 3 years follow up and a significant negative correlation between endothelial cell loss and ACD. And so they recommend caution while operating on young patients who narrowly meet the inclusion criteria for ACD and ECDs. Pop and Payette [24], in 765 eyes in their study have not observed a decrease in ECD up to 2 years of follow up after anterior chamber Artisan myopia lens. However Landesz et al. [25], in their study reported a progressive endothelial cell loss of $5.5 \%$ at 6 months follow uo, $7.21 \%$ at 12 months follow up, and $9.1 \%$ at the end of the secondd year follow up after surgery. Tahzib 
et al. [26], found that there was no significant endothelial cell loss over time. On the contrary, their study group showed a surprising unexplained result a relative increase in ECD, 1 year and 10 years after the procedure. Also, Tehrani [18], in his study confirmed that injection of ophthalmic viscosurgical material before inserting the lens into the anterior chamber and also prior enclavation, in order to ensure added protection to the endothelium. Coullet et al. [27], have found no differences in central endothelial cell densities after 1 year in Artisan- and Artiflex-treated eyes Although the foldable feature of the optic of the Artiflex lens with a potentially mobile nature may decrease the tolerance of the endothelium,. Also, using Scheimpflug photography, Kohnen [28], demonstrated that the Artiflex lens has a significantly greater distance to the endothelium than the Artisan lens, possibly providing better safety against endothelial cell loss. In the multicenter European study the mean endothelial cell loss in patients with Artiflex lenses, was $0.05 \%$ at 6 months, $1.79 \%$ at 1 year, and $1.07 \%$ at 2 years. In the Hashemi $\mathrm{H}$ et al., in their one year follow up study ECC showed an average decrease of $3.04 \%$ at the end of the first year [29].

In the current study, mean postoperative endothelial cell losses were found to be $1.6 \%$ at the first month, $2.23 \%$ at the first year and $3.9 \%$ at the second year and 5.4 after three years. It may be due to younger mean age of our group plenty use of adhesive viscoelastic with more protection of the endothelium however longer followup are needed to evaluate the tolerance of the endothelium against Artiflex and Veriflex in the long term.

Multiple factors attribute the complication of PIOLs, the main cause of the expected complications are due to the position of the PIOL in the anterior chamber. Iris-fixated PIOLs have been associated with several surgical complications such as elevation of IOP either transient or perminant, cataracts, pigment deposits, pupil distortion and chronic anterior segment inflammation [17]. Glaucoma may be attributed to the design of the PIOL with iris fixation associated with chronic anterior segment inflammation due to irritation of the iris tissue. Also, myopic patients, may be at more risk to develop different types of chronic open-angle glaucoma [30].

In this study, elevation of IOP was observed in two eyes in the same patient, the increased intraocular pressure responded well to topical antiglaucoma drops with decrease frequency of steroid drops which suggesting steroid induced glaucomain this patient with no evidence of increased intraocular pressure along the follow up period in patients underwent foldable anterior chamber PIOL.

Pigment deposits in PIOL may be due to the silicon optic material that is used in Artiflex and Veriflex [22], the real reason of pigment dispersion and chronic inflammatory reactions in cases of anterior chamber PIOL and that reactions may be due to an abnormal pressure on the iris tissue which is compressed between the crystalline lens from one side and the PIOL from the other side $[31,32]$. Another study [33], confirmed that mechanical irritation of the iris tissue occurring during pupillary movement due to the decreased vault between the optic-haptic junction of the lens and the iris plane. Short-term usage of topical corticosteroids was recommended in order to decrease the incidence of precipitates. Also, some surgeons used an intraoperative subconjunctival or subtenon corticosteroid depot injection [22]. In the present study, non-pigmented precipitate in one eye (4\%) due to iritis and minimally decrease vision by one line on the snellens chart, pigmented precipitates were observed in 4 eyes (16\%) eyes. All these cases treated with more frequent topical corticosteroid agents. In the second postoperative year, the pigment dispersion was still present in all eyes and after 3 years it persist in all eyes but decrease in number and size however, this precipitate did not effect on visual acuity. Close contact and frequent friction between Artiflex lens and the iris tissue may be the cause of pigment dispersion or due to release of pigment from incarcirated iris tissue as noticed in the patient who underwent refixation we noticed iris atrophy with loss of iris pigment. In order to decrease the risk, the surgeon should eliminate excessive and vigeorus manipulations within the eye during the implantation procedure and enclavation of the optimal iris tissue to the claws of the PIOL not excessive and not minimal to avoid dislocation.

One of recorded complication in this study is the second surgery to refixate the PIOL due to minimal iris tissue with impending dislocation of the PIOL the cause of this complication was not opvious however mild trauma even not mentioned by the patient may be the cause of this complication.

\section{Conclusion}

In this study, we conclude that anterior chamber foldable phakic IOL (Artiflex or Veriflex) implantation is an effective and safe surgical procedure with stable refraction for the management of myopia unsuitable for LASIK along more than three years follow up period with minimal complications and we can avoid major complications by strict and regular follow up. However further long-term studies are needed, to evaluate the safety profile of this PIOL for correction of myopia.

\section{References}

1. Pesudovs K, Garamendi E, Elliott DB (2006) A quality of life comparison of people wearing spectacles or contact lenses or having undergone refractive surgery. J Refract Sure 22: 19-17.

2. Awadein A, Habib AE (2013) ICL versus Veriflex phakic IOL for treatment of moderately high myopia: randomized paired-eye comparison. J Refract Surg 29: 445-452.

3. Jabbur NS, Sakatani K, O'Brien TP (2004) Survey of complications and recommendations for management in dissatisfied patients seeking a consultation after refractive surgery. J Cataract Refract Surg 30: 1867-1874.

4. Bamashmus MA, Hubaish K, Alawad M, Alakhlee H (2015) Functional outcome and patient satisfaction after laser in situ keratomileusis for correction of myopia and myopic astigmatism. Middle East Afr J Ophthalmol 22: 108-114.

5. Lazon de la Jara P, Erickson D, Erickson P, Stapleton F (2011) Visual and nonvisual factors associated with patient satisfaction and quality of life in LASIK. Eye (Lond) 25: 1194-1201.

6. Barsam A, Allan BD (2014) Excimer laser refractive surgery versus phakic intraocular lenses for the correction of moderate to high myopia. Cochrane Database Syst Rev CD007679.

7. Marinho A, Pinto MC, Vaz F (2000) Phakic intraocular lenses: which to choose. Curr Opin Ophthalmol 11: 280-288.

8. Sanders DR (2007) Matched population comparison of the Vision implanTable collamer lens and standard LASIK for myopia of -3.00 to -7.88 diopters. J Refract Surg 23: 537-553. 
9. Schallhorn S, Tanzer D, Sanders DR, Sanders ML (2007) Randomized prospective comparison of Visian toric implanTable collamer lens and conventional photorefractive keratectomy for moderate to high myopic astigmatism. J Refract Surg 23: 853-867.

10. Ripandelli G, Billi B, Fedeli R, Stirpe M (1996) Retinal detachment after clear lens extraction in 41 eyes with high axial myopia. Retina 16: 3-6.

11. Ozertürk Y, Kubaloglu A, Sari ES, Koytak A, Capkin M, et al. (2012) Foldable iris-fixated phakic intraocular lens implantation for the correction of myopia: two years of follow-up. Indian J Ophthalmol 60: 23-28.

12. Chen LJ, Chang YJ, Kuo JC, Rajagopal R, Azar DT (2008) Metaanalysis of cataract development after phakic intraocular lens surgery. J Cataract Refract Surg 34: 1181-1200.

13. Fechner PU, Strobel J, Wichmann W (1991) Correction of myopia by implantation of a concave Worst-iris claw lens into phakic eyes. Refract Corneal Surg 7: 286-298.

14. Alexander L, John M, Cobb L, Noblitt R, Barowsky RT (2000) U.S. clinical investigation of the Artisan myopia lens for the correction of high myopia in phakic eyes: report of the results of phases 1 and 2, and interim phase 3 . Optometry 71: 630-642.

15. Bartels MC, Saxena R, van den Berg TJ, van Rij G, Mulder PG, et al. (2006) The influence of incision-induced astigmatism and axial lens position on the correction of myopic astigmatism with the Artisan toric phakic intraocular lens. Ophthalmology 113: 1110-1117.

16. Güell JL, Vázquez M, Malecaze F, Manero F, Gris O, et al. (2003) Artisan toric phakic intraocular lens for the correction of high astigmatism. American journal of ophthalmology 136.3: 442-447.

17. Dick HB, Tehrani M, Aliyeva S (2004) Contrast sensitivity after implantation of toric iris-claw lenses in phakic eyes. J Cataract Refract Surg 30: 2284-2289.

18. Tehrani M, Dick HB (2005) Short-term follow-up after implantation of a foldable iris-fixated intraocular lens in phakic eyes. Ophthalmology 112 : 2189-2195.

19. Kohnen T (2000) Searching for the perfect phakic intraocular lens. J Cataract Refract Surg 26: 1261-1262.

20. Maloney RK, Nguyen LH, John ME (2002) Artisan phasic intraocular lens for myopia: Short-term results of a prospective, multicenter study: The Artisan Lens Study Group. Ophthalmology 109: 1631-1641.

21. Budo C, Hessloehl JC, Izak M, Luyten GP, Menezo JL, et al. (2000)
Multicenter study of the Artisan phakic intraocular lens. J Cataract Refract Surg 26:1163-1171.

22. Dick HB, Budo C, Malecaze F, Güell JL, Marinho AA, et al. (2009) Foldable Artiflex phakic intraocular lens for the correction of myopia: Two-year followup results of a prospective European multicenter study. Ophthalmology 116 : 671-677.

23. Saxena R, Boekhoorn SS, Mulder PG, Noordzij B, van Rij G, et al. (2008) Long-term follow-up of endothelial cell change after Artisan phakic intraocular lens implantation. Ophthalmology 115: 608-613.

24. Pop M, Payette $Y$ (2004) Initial results of endothelial cell counts after Artisan lens for phakic eyes: An evaluation of the United States Food and Drug Administration Ophtec Study. Ophthalmology 111: 309-317.

25. Landesz M, van Rij G, Luyten G (2001) Iris-claw phakic intraocular lens for high myopia. J Refract Surg 17: 634-640.

26. Tahzib NG, Nuijts RM, Wu WY, Budo CJ (2007) Long-term study of Artisan phakic intraocular lens implantation for the correction of moderate to high myopia: Ten-year follow-up results. Ophthalmology 114: 1133-1142.

27. Coullet J, Guëll JL, Fournié P, Grandjean H, Gaytan J, et al. (2006) Irissupported phakic lenses (rigid vs foldable version) for treating moderately high myopia: Randomized paired eye comparison. Am J Ophthalmol 142: 909-916.

28. Kohnen T, Cichocki M, Koss MJ (2008) Position of rigid and foldable irisfixated myopic phakic intraocular lens models evaluated by Scheimpflug photography. J Cataract Refract Surg 34: 114-120.

29. Hashemi H1, Taherzadeh M, Khabazkhoob M (2013) Correction of high myopia with foldable Artiflex Phakic intraocular lenses: 1 year follow-up results. Acta Med Iran 51: 620-625.

30. Lefrancois A (1994) Myopie forte et glaucoma. In: Mondon $\mathrm{H}$, Metge $\mathrm{P}$, editors. La Myopie Forte. 27: 413-446.

31. Alió JL, Mulet ME, Shalaby AM (2002) Artisan phakic iris claw intraocular lens for high primary and secondary hyperiopa. J Refract Surg 18: 697-707.

32. Baïkoff G, Bourgeon G, Jodai HJ, Fontaine A, Lellis FV, et al. (2005) Pigment dispersion and Artisan phakic intraocular lenses: Crystalline lens rise as a safety criterion. J Cataract Refract Surg 31: 674-680.

33. Tahzib NG, Eggink FA, Frederik PM, Nuijts RM (2006) Recurrent intraocular inflammation after implantation of the Artiflex phakic intraocular lens for the correction of high myopia. J Cataract Refract Surg 32: 1388-1391.

Copyright: (C) 2016 AlSamman AH. This is an open-access article distributed under the terms of the Creative Commons Attribution License, which permits unrestricted use, distribution, and reproduction in any medium, provided the original author and source are credited. 